\title{
ESTIMATE PASSENGER CAR EQUIVALENT OF VEHICLES PERFORMING MANOEUVRE TO ENTER OR LEAVE LEGAL AND ILLEGAL ON-STREET PARKING
}

\author{
Ahmed Elkafoury ${ }^{1}$, Islam Abo El-Naga² \\ ${ }^{1,2}$ Department of Public Works Engineering, Faculty of Engineering, Tanta University, Egypt
}

Received 26 December 2019; accepted 17 March 2020

\begin{abstract}
For transportation and traffic designers, the existence of a method to convert effective vehicles into reference Passenger Car Equivalent (PCE) is an essence. Both legal and illegal on-street parking events are associated with manoeuvre during entering or leaving the parking spot. This manoeuvre is highly affecting the traffic performance of the street link. This paper introduces a method for determining the Passenger Car Equivalent (PCE) for vehicles that perform a manoeuvre for on-street parking. The $M / M / \infty$ queuing model together with the Greenshield traffic state model are used to estimate the effect of the delay and the capacity drop caused by a manoeuvring event on the traffic flow continuity in case of entering or leaving a legal and illegal on-street parking space. Two design charts are introduced to show the values of the average passenger car equivalent for different manoeuvre times and manoeuvring frequencies combinations for both legal and illegal parking types. PCE values of vehicles manoeuvre for legal parking experience fluctuation throughout the link's volume to capacity $\left(\frac{D}{C}\right)$ ranges. It is found that, for lower $\frac{D}{C}$ ratios and up to $\frac{D}{C}$ of about 0.33, PCE of vehicles manoeuvre for legal parking types shows a slight upward trend. The smallest PCE of vehicles manoeuvre for legal parking is noticed at $\frac{D}{C}$ of nearly 0.41 . Then, the increase of $\underline{D}$ is accompanied with an increase of PCE supported by the increase of the link's average travel time. During manoeuvring for illegal on-street parking, the section loses one more lane capacity for the duration of the manoeuvre. Thus, the traffic demand outrace the capacity at $\frac{D}{C}$ of about 0.69 which is earlier than the case of legal parking which influences the PCE value. Sensitivity analysis indicated that the time of the manoeuvring event is the major cause of uncertainty in the predicted PCE of a parking manoeuvring vehicle.
\end{abstract}

Keywords: passenger car equivalent, on-street parking manoeuvre, $\mathrm{M} / \mathrm{M} / \infty$ queuing model, Greenshield traffic model.

\section{Introduction}

For transportation planners, figuring out a methodology to convert vehicles into reference Passenger Car Equivalent (PCE) is an essence for the analysis and management of road networks. A PCE represents the number of passenger cars that can substitute one vehicle of a specific type in a specific traffic situation. PCE was first launched in 1965 in the Highway capacity Manual (HCM) to convert the influence of buses and heavy

${ }^{1}$ Corresponding author: kaforiengin@f-eng.tanta.edu.eg 
vehicles that causes speed reduction into passenger cars units. Then, the 2010 version of $\operatorname{HCM}(\mathrm{TRB}, 2010)$ confirmed wider notion of the PCE and interpreted it as the number of passenger cars which will result in the same operational condition as a single heavy vehicle. Different research studies (Biswas et al., 2017; Arasan et al., 2010; Cao, 2012; Chandra et al., 2003; Jin, 2015; Biswas et al., 2017; Giuffre, 2018) conducted for the purpose of estimating the (PCE) values in different urban traffic conditions showed that PCEs are dynamic variables that are affected by traffic characteristics and flow parameters; speed, density, headway, delay, etc. It is known that vehicles movements are at a clear nexus of decreasing travelling speed on road links, increasing time delay, producing emissions and noise, and increasing the rate of accidents (Elkafoury et al., 2015). Thus, PCE for the effect of one vehicle has been a research interest. And based on the impact chosen for PCE estimation, different approaches are conceptualized. The PCE for the congestion effect of passenger cars and trucks and their impedance on reducing the intersection capacity at signalized intersections has been the core research problem in (Sarraj, 2014), (Nassiri et al., 2017), (Mohan et al., 2017) and (Radhakrishnan et al., 2011). PCEs for the same effect have been investigate for undivided intercity roads in (Mardani et al., 2015), for tunnel traffic in (Ahmed et al., 2017), for heterogeneous expressway traffic in (Yeung et al., 2015), and for heavy vehicles on roundabouts in (Lee, 2015) and (Giuffre, 2016). In addition, Cen et al. (2016) introduced a method for estimating a passenger car emission unit. A noise-based PCE values were developed in (Sasikumar $e t$ al., 2018).

For each automated trip, vehicles demand a parking space at its origin and its destination.
Relating, the on-street parking problem has been a prevalent worry since the advent of vehicles as it is the convenient and prevailing among different parking prototypes. This is related to the preference of drivers to park on-street even if all parking spaces are almost occupied. In developing countries, with the increase of car ownerships and road-based transportation modes, parking related problems are alarming and will grow up if the parking demand and behaviour is not considered in design. In urban areas in developing countries, it is estimated that $95 \%$ of vehicle parks every day in three different places (Biswas et al., 2017; Stephen et al., 2006; Greg, 2006). Of which, each parking process incorporates the behaviour of entering and leaving the parking space.

Relating, on-street parking is the major traffic speed and capacity redactor as opposed to other factors pedestrians and non-motorized vehicles (Munawar, 2011). It is estimated that the travel speed falls by about $13 \mathrm{~km} /$ $\mathrm{hr}$ for each increase of $100 \mathrm{veh} / \mathrm{km}$ of onstreet parking density. It is also evident that almost $14 \%$ of congestion cases on urban street links occur in locations at which onstreet parking and parking manoeuvring takes place (Fadairo, 2013). Generally, the capacity loss of road links decreases with the decrease of the on-street parking intensity. The frequency of parking manoeuvre events (entering or leaving an on-street parking spot) is most momentous parking parameter that influence the link travel speed (Salini et al., 2016). Previous study resulted in that $35 \%$ of on-street parking manoeuvres can limit the capacity of the link to about $35 \%$ of the full capacity (Bulactial et al., 2013). And in case of both side parking on two lane road, the capacity can drop by $90 \%$ (John et al., 2009). Furthermore, on-street parking is a preeminent cause of road crash and accidents. 
Vehicles leaving the parking spot baking into the flow, and vehicles slowing down and manoeuvre back to enter the parking spot, both are noticed as source of accidents. This type of accidents represents nearly $30 \%$ and $19 \%$ of accidents on one way and two way streets respectively (Biswas et al., 2017). 2\% of these accidents result in fatalities.

On the other hand, the literature shows that scholars performed different studies to understand and analysis the effect of onstreet parking on vehicles flow performance. Cao et al. (2016) developed a model to analyze the change in intersection service rate due to on-street parking manoeuvre. Traffic operation at parallel and angle onstreet parking facilities were investigated by Saad et al. (2004). On the other hand, Xiaofei et al. (2011) studied the delay caused by on-street parking allowed at signalized intersections. Similar research by Gu et al. (2014) has been applied to bus stops near signalized intersections. The influence of parking availability on traffic performance (speed and density) has also investigated by Cao et al. (2015).

Overall, and up to the knowledge of the authors, no attention has been given to the estimation of PCE of cars that perform manoeuvre for parking (slow down to enter an on-street parking spot or cuts the edge lane to leave an on-street parking spot). The estimation of such effect is important for considering this behaviour in design of urban streets in order to increase the reliability of the projects and increase its efficiency. In this paper, a new methodology for estimating the effect and PCE values of cars that perform manoeuvre for entering or leaving different types of on-street parking (legal and illegal) is introduced. The PCE effect is a conversion of the trip delay caused by the on-street manoeuvre effect which is mathematically modelled. The paper also produces design chats and predictive models that estimate the (PCE) of cars manoeuvring for entering or leaving an on-street parking that can be utilized by transportation and traffic engineers for urban streets design process.

The remaining of this paper is outlined as follows. Section two illustrate the queuing model used to describe delay caused onstreet links due to parking manoeuvring events. Section three, represents the formation of the PCE estimation model. Then, Section four represents the application of the developed model on a 6-lane divided urban street in Delhi -India. The analysis of the results in addition to the development of PCE regression models and design maps are included in Section Five. Finally, Section Six concludes the works.

\section{Developing the Queuing Model of Links that Examine Parking Manoeuvre}

Melike et al. (2006 and 2009) introduced a queuing model that describes the delay effect of an event (for example: incident, vehicle demobilization, hazardous spills, etc.) on traffic flow served on a roadway section. Based on a modification of $M / M / C$ model, $M / M / \infty$ queuing model introduces the arrival and departure sequences given a Poisson distribution while the servers (space that can be occupied by single vehicle on the link segment) are infinite. These servers go into work at the time the vehicle enters the link unless it is interrupted by an event that forces vehicle to slow down to follow a lane change behaviour or even fully stops.

The event of vehicles that manoeuvre for parking is considered as a flow 
interruption occurrence that delays the flow. To investigate the impact of parking manoeuvring on traffic flow, $M / M / \infty$ is utilized. At manoeuvring, the service rate of the server changes from the normal service rate $(\mu)$ to the below normal service rate $(\mu \backslash)$. Thus, in case of parking manoeuvring event, the average arrival time on the link changes from $(1 / \mu)$ to $(1 / \mu \backslash)$. In such case, $M / M / \infty$ model estimates the expected number of vehicles on the link $(\mathrm{E}(\mathrm{X}))$ as in Equation 1. In this equation, the interruption is assumed to happen with Poisson process behavior of frequency $f$, and the clearance times is following a rate $r$ of identical i.i.d random exponential distribution. In addition, the vehicle arrives according with homogeneous Poisson process of a rate $(\lambda)$. The model handles the previous equation to express the average travel time on the link (W) as in Equation 2.

$$
\begin{aligned}
& E(X)=\frac{\lambda}{\mu}+\frac{\lambda \cdot f \cdot(\mu-\mu \backslash)}{\mu^{2} \cdot(r+f)} \cdot\left(1+\frac{(\mu+f) \cdot(\mu-\mu \backslash)}{(r \cdot \mu+f \cdot \mu \backslash+\mu \cdot \mu \backslash)}\right) \\
& W=\frac{E(X)}{\lambda}=\frac{1}{\mu}+\frac{. f \cdot(\mu-\mu \backslash)}{\mu^{2} \cdot(r+f)} \cdot\left(1+\frac{(\mu+f) \cdot(\mu-\mu \backslash)}{(r \cdot \mu+f \cdot \mu \backslash+\mu \cdot \mu \backslash)}\right)
\end{aligned}
$$

So as to modify the $M / M / \infty$ queuing model to capture the vehicular traffic flow, characteristics in Equations 1 and 2 are transferred to parameters (given in Table 1) of the flow on the link. Where $\mathrm{D}$ is the hourly traffic demand arrives at the link (veh/hr), $\mathrm{L}$ is the link length $(\mathrm{km}), \mathrm{m}$ is the average duration of one manoeuvring event (hr), $\mathrm{v}$ is the average speed on the link $(\mathrm{km} / \mathrm{hr})$ in case of no parking manoeuvring events, and $v^{`}$ is the speed on the link section $(\mathrm{km} / \mathrm{hr})$ in case of parking manoeuvring events. Therefore, under the force of parking manoeuvring events, the link's average number of vehicles $(\mathrm{N})$ and link's average travel time $\left(\mathrm{t}_{\mathrm{m}}\right)(\mathrm{hr})$ are estimated by Equation 3 and 4 respectively where $f$ is the frequency of existing of parking manoeuvring event (manoeuvre/hr).

$$
\begin{aligned}
& \mathrm{N}=\frac{\mathrm{D} \cdot \mathrm{L}}{\mathrm{v}}+\frac{\mathrm{D} \cdot \mathrm{f} \cdot\left(\frac{\mathrm{v}}{\mathrm{L}}-\frac{\mathrm{v} \backslash}{\mathrm{L}}\right)}{\frac{\mathrm{v}^{2}}{\mathrm{~L}} \cdot\left(\frac{1}{\mathrm{~m}}+\mathrm{f}\right)} \cdot\left(1+\frac{\left(\frac{\mathrm{v}}{\mathrm{L}}+\mathrm{f}\right) \cdot\left(\frac{\mathrm{v}}{\mathrm{L}}-\frac{\mathrm{v} \backslash}{\mathrm{L}}\right)}{\left(\frac{1}{\mathrm{~m}} \cdot \frac{\mathrm{v}}{\mathrm{L}}+\mathrm{f} \cdot \frac{\mathrm{v}}{\mathrm{L}}+\frac{\mathrm{v}}{\mathrm{L}} \cdot \frac{\mathrm{v}}{\mathrm{L}}\right)}\right) \\
& \mathrm{t}_{\mathrm{m}}=\frac{\mathrm{N}}{\mathrm{D}}=\frac{\mathrm{L}}{\mathrm{v}}+\frac{\mathrm{f} \cdot\left(\frac{\mathrm{v}}{\mathrm{L}}-\frac{\mathrm{v} \backslash}{\mathrm{L}}\right)}{\frac{\mathrm{v}^{2}}{\mathrm{~L}} \cdot\left(\frac{1}{\mathrm{~m}}+\mathrm{f}\right)} \cdot\left(1+\frac{\left(\frac{\mathrm{v}}{\mathrm{L}}+\mathrm{f}\right) \cdot\left(\frac{\mathrm{v}}{\mathrm{L}}-\frac{\mathrm{v} \backslash}{\mathrm{L}}\right)}{\left(\frac{1}{\mathrm{~m}} \cdot \frac{\mathrm{v}}{\mathrm{L}}+\mathrm{f} \cdot \frac{\mathrm{v} \backslash}{\mathrm{L}}+\frac{\mathrm{v}}{\mathrm{L}} \cdot \frac{\mathrm{v}}{\mathrm{L}}\right)}\right)
\end{aligned}
$$

Table 1

Modifications of $M / M / \infty$ Queuing Model Parameters for Representing Traffic Flow on the Link

\begin{tabular}{|c|c|c|c|c|}
\hline Parameters of Equation (1) and (2) & $\lambda$ & $\mu$ & $\mu \backslash$ & $\mathrm{r}$ \\
\hline Replacement with Traffic Flow Parameters & $\mathrm{D}$ & $\frac{\mathrm{v}}{\mathrm{L}}$ & $\frac{\mathrm{v} \backslash}{\mathrm{L}}$ & $\frac{1}{\mathrm{~m}}$ \\
\hline
\end{tabular}

\section{Passenger Car Equivalent (PCE) Model}

Practically, for roadway users, the driving behaviour during entering or leaving an on-street parking space (slowing down and acceleration to manoeuvre to perform safe entrance or leaving for parking space) is examined to cause significant time delay for other vehicles in the stream. It is considered as high frequency short duration events that affects the average travel time. Accordingly, in this study, the time delay is chosen to be the concern impact for estimating PCE for cars manoeuvring for on-street parking. Benekohal (2000) developed a delay-based model to estimate the PCE of heavy vehicles at signalized intersection according to the additional time delay induced by heavy vehicle unit to the delay of a passenger car in a stream of passenger cars only. The same concept can be utilized in case of a manoeuvring behaviour of a car for entering 
or leaving an on-street parking in conformity with that the capacity reduction caused by a parking manoeuvring car is transformed to a delay as that caused by a heavy vehicle. The PCE formula can be expressed as in Equation 5 where $\Delta \mathrm{d}_{\mathrm{m}}$ is the additional delay (sec/veh) caused by one parking manoeuvre and $d_{b}$ is the average delay (sec/veh) of a passenger car in a stream of no parking manoeuvring cars.

$P C E=1+\frac{\Delta d_{m}}{d_{b}}$

In order to calculate $\mathrm{d}_{\mathrm{b}}$ and $\Delta \mathrm{d}_{\mathrm{m}}$, the link's average travel time is required to be determined for any specific traffic demand. For cases of uninterrupted flow, Greenshield's flow-speed relationship (Greenshields et al., 1935) shown in Equation 6 is appropriate for this purpose, where $\mathrm{k}_{\mathrm{j}}$ and $\mathrm{v}_{\text {free }}$ are the link's jam density ( $\mathrm{veh} / \mathrm{km})$ and free flow speed $(\mathrm{km} / \mathrm{hr}$ ) respectively. This equation can be resolved for $\mathrm{v}$ as in Equation 7. Once $\mathrm{v}$ is determined, the link's average travel time can be derived by dividing the link length by v. It is worthy to mention here that the queue length in case of no parking manoeuvring events is $\frac{\mathrm{DL}}{\mathrm{v}}$ (vehicles). This value can be derived from Equation 3 considering $\mathrm{v}^{\prime}=\mathrm{v}$. Then, $\mathrm{d}_{\mathrm{b}}(\mathrm{sec} /$ veh) and $\Delta \mathrm{d}_{\mathrm{m}}(\mathrm{sec} / \mathrm{veh})$ are estimated by Equation 8 and 9 where $t_{\text {free }}$ and $t_{b}$ are the free flow travel time and average travel time in case of no parking manoeuvring respectively.

$$
\begin{aligned}
& D=v \cdot k_{j}-\left(\frac{k_{j}}{v_{\text {free }}}\right) \cdot v^{2} \\
& v=\frac{v_{\text {free }}}{2 k_{j}} \cdot\left(k_{j}+\sqrt{k_{j}^{2}-\frac{4 k_{j} \cdot D}{v_{\text {free }}}}\right) \\
& d_{b}=\frac{\left(t_{b}-t_{\text {free }}\right)}{\frac{D L}{v}}
\end{aligned}
$$

$\Delta d_{m}=\frac{\left(t_{m}-t_{\text {free }}\right)-\left(t_{b}-t_{\text {free }}\right)}{f}$

During the parking manoeuvre of legal parking, the acting vehicle closes a point on the lane holding the manoeuvring event for a specific period of time. Meanwhile, the capacity of cross section drops by an amount of one lane capacity (veh/hr). During manoeuvring events of illegal parking, two lanes are close; the parking lane and the lane adjacent to the parking lane in which the manoeuvring event takes place. Thus the capacity of cross section drops by an amount of two lane capacities. This lane drop events is a cause of changes for the boundary characteristics of the link, and new Greenshield's flow-density relation holds. Figure 1 illustrates the flow-density and speed-density relation in case of no parking manoeuvring and during parking manoeuvre event. If the capacity of the segment before the lane drop is $\mathrm{C}$ and the capacity of the segment after the lane drop is $C$, one of two cases of estimating the value of $v^{\backslash}$ exists:

$v \backslash=\left\{\begin{array}{r}v(D)=\frac{v_{\text {free }}}{2 k_{j}} \cdot\left(k_{j}+\sqrt{k_{j}{ }^{2}-\frac{4 k_{j} . D}{v_{\text {free }}}}\right), D \leq C \backslash \\ v\left(C^{\backslash}\right)=\frac{v \backslash_{\text {free }}}{2}, D>C \backslash\end{array}\right.$

Where $v_{\text {free }}$ is the free flow speed for the Greenshield's model in case of parking manoeuvre, $v \backslash_{\text {free }}=\frac{4 \mathrm{C} \backslash}{\mathrm{k}_{\mathrm{j}}}$. The first case represents the situation of uncongested state when the traffic demand is less than C`. In such case, the average speed on the link is the speed in case of uncongested flow $(\mathrm{v}(\mathrm{D}))$. On the contrary, the second case demonstrates the situation of congested state when traffic demand is higher than $C \backslash$. Here, the flow at the section equals $C^{\backslash}$, and the overflowing vehicles forms a queue 
behind the manoeuvring point. Thus, $\mathrm{v}^{\prime}$ is determined by the congested conditions using $\left(\mathrm{v}\left(\mathrm{C}^{\prime}\right)\right)$. It is important to state here the assumption that the jam density of the link will not change during the manoeuvring event as this event will not prevent the existence of vehicles in the upstream and downstream, but it will prevent its flow.
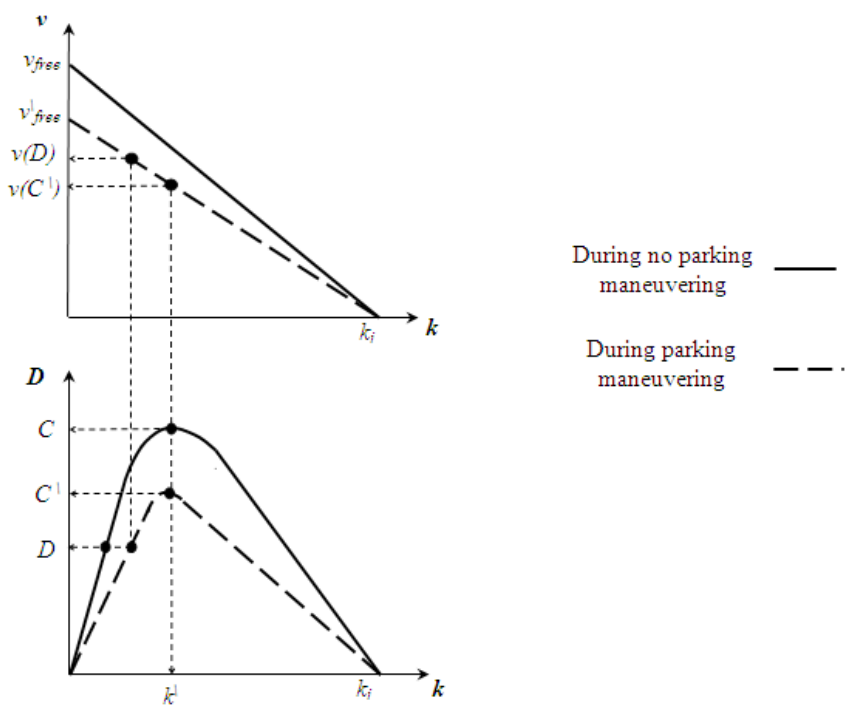

Fig. 1.

Flow-Density and Speed-Density Relation of the Street Link during Parking Manoeuvre and no Parking Manoeuvre Event

\section{Application of the PCE Model on a Case Study}

The effect of manoeuvring for parking is explored for the most recorded patterns of manoeuvring in previous studies for on-street parking. This encloses 10 different patterns of manoeuvre for 3 on-street parking types; legal parallel parking (L-Par) which represents parallel parking in legal on-street parking stalls, legal angle parking (L-Ang) which represents parking in legal on-street angle parking stalls, and illegal parallel parking (IL-Par) that represents parallel parking in lanes that are not specified for parking. The manoeuvring event is classified into Entering (En) the parking stall and Leaving (Le) the parking stall. Each patterns of manoeuvring for entering or leaving the parking is described by a letter (P) and a number. For L-Par and IL-Par types of on-street parking, there exist 4 patterns of manoeuvring for entering. Each reports the position of parking regarding the parking row (front, end, between vehicles) in addition to the direction of movement during entering. There exist only two patterns of manoeuvring for leaving. These patterns are described in Table 2. Regarding L-Ang parking type, each of entering and leaving manoeuvre are utilized by two patterns enclosed in Table 3. Data for the average duration of each manoeuvring pattern $(\mathrm{m})$ $(\mathrm{sec})$ is extracted from Samaher (1999 and 2004) and Fadhil et al. (2017) who provide 
manoeuvring time for each pattern bases on field observations (Table 4). In case of reporting different manoeuvring times for the same pattern, an average value of both is used. The pattern 2 of entering illegal onstreet parking stall (En-IL-Par-P2) has no recorded time for manoeuvring in Table 4. This is referred to the rarity of this event in collected samples in literatures.
The developed method is applied for a 6-lane divided urban street which has a Greenshield's boundaries as follows (Dhamaniya et al., 2017): $\mathrm{v}_{\text {free }}=60.18(\mathrm{~km} / \mathrm{hr}), \mathrm{k}_{\mathrm{j}}=403.89$ (PCE/km), and capacity of 6075 (PCE/ $\mathrm{hr}$ /direction) with a lane capacity of 2025 (PCE/hr/lane). Each experiment has been performed for different values of $f(10,20,30$, and 40 (manoeuvre/hr)).

\section{Table 2}

Different Patterns of Manoeuvre for Entering and Leaving Legal Parallel on-street Parking

\begin{tabular}{|c|c|c|}
\hline & Entering L-Par and IL-Par on-street Parking Types \\
\hline (P1) In front of a parked & (P2) Reveres park between & (P3) Between two parked \\
\hline vehicle & vehicles \\
\hline
\end{tabular}

\section{Table 3}

Different Patterns of Manoeuvre for Legal Angel on-street Parking

\begin{tabular}{|c|c|c|c|}
\hline \multicolumn{2}{|c|}{ Entering } & \multicolumn{2}{|c|}{} \\
\hline $\begin{array}{c}\text { (P1) Parking from } \\
\text { adjacent lane }\end{array}$ & $\begin{array}{c}\text { (P2) Parking from non- } \\
\text { adjacent lane }\end{array}$ & $\begin{array}{c}\text { (P1) Reveres to leave } \\
\text { parking to the adjacent } \\
\text { lane }\end{array}$ & $\begin{array}{c}\text { (P2) Reveres to leave } \\
\text { parking to non-adjacent } \\
\text { lane }\end{array}$ \\
\hline
\end{tabular}


Table 4

Manoeuvre Time (sec) of Each Pattern for Different On-street Parking Types

\begin{tabular}{|c|c|c|c|c|}
\hline \multicolumn{2}{|c|}{ Parking Types } & L-Par & L-Ang & IL-Par \\
\hline \multirow{3}{*}{$\begin{array}{c}\text { Pattern of Manoeuvring for } \\
\text { Entering }\end{array}$} & $(\mathrm{P} 1)$ & $4.2 \& 7.7$ & 4.9 & 4.5 \\
\cline { 2 - 5 } & $(\mathrm{P} 2)$ & 21.2 & 4.9 & - \\
\cline { 2 - 5 } & $(\mathrm{P} 3)$ & $7.7 \& 12.6$ & - & 6.3 \\
\cline { 2 - 5 } & $(\mathrm{P} 4)$ & $3.4 \& 6$ & - & 4.4 \\
\hline \multirow{2}{*}{$\begin{array}{c}\text { Pattern of Manoeuvring for } \\
\text { Leaving }\end{array}$} & $(\mathrm{P} 1)$ & $6.3 \& 4.6$ & 9.6 & 5.1 \\
\cline { 2 - 5 } & $(\mathrm{P} 2)$ & 5.5 & 11.8 & 3.9 \\
\hline
\end{tabular}

\section{Analysis of Results \& Discussion}

Throughout all flow to capacity ratios $\frac{D}{C}$ and for almost all manoeuvring patterns, it is indicated that highest Average Passenger Car Equivalent $\left(\mathrm{PCE}_{\mathrm{av}}\right)$ values are related to manoeuvring frequencies of 10 (manoeuvre/ hr). By contrast, smallest $\mathrm{PCE}_{\mathrm{av}}$ values are related to manoeuvring frequencies of 40 (manoeuvre/hr). In addition, it is noticed that manoeuvring pattern En-L-Par-P2 has the immense effect on traffic flow and section capacity. In which, every vehicle has $\mathrm{PCE}_{\mathrm{av}}$ of $1.99,1.94,1.91$, and 1.87 for $\mathrm{f}$ of 10 , 20,30 , and 40 (manoeuvre/hr) respectively. This is addressed to: first, the high value of manoeuvre times $(\mathrm{m})$ of these patterns as opposed to other manoeuvring patterns. The second highest $\mathrm{PCE}_{\mathrm{av}}$ values are observed for Le-L-Ang-P2. This is explained by; first, its high value of $\mathrm{m}$, and second, the leaving behavior in which the manoeuvring vehicle closes both the parking lane and the adjacent lane. In contrast, En-L-Par-P4 pattern has the lowest average effect on traffic flow. It has the lowest $\mathrm{PCE}_{\mathrm{av}}$ of all manoeuvring patterns with a value of 1.2 at $f=10,30$, and 40 (manoeuvre/hr). En-L-Ang-P1 and En-LAng-P2 has the same PCE for all values of $f$ due to the similarity of $\mathrm{m}$ for both patterns. See Figure 2.
In terms of the Standard Deviation (SD) of $\mathrm{PCE}_{\mathrm{av}}$ for all manoeuvring patterns (Figure 3 ), the analysis indicates that $S D$ vales of $\mathrm{PCE}_{\mathrm{av}}$ for parking manoeuvring vehicles for illegal types are smaller than those of legal types. In addition, for both groups of legal parking and illegal parking, SD increases as the $\mathrm{PCE}_{\mathrm{av}}$ increases and vice versa. For any manoeuvre type, the variation of $S D$ values is very small for manoeuvring frequencies of 20,30 , and 40 (manoeuvre/hr). Overall, the smallest $S D$ values are obtained at manoeuvring frequencies of 10 and 40 (manoeuvre/hr) for manoeuvring patterns of legal and illegal parking types accordingly. Also, it is noticed that manoeuvring pattern En-L-Par-P2 has the highest SD values (0.19) while the lowest $S D$ records are obtained for the pattern Le-IL-Par-P2 (0.016) which has the smallest value of manoeuvre times among all patterns $(3.9 \mathrm{sec})$ and the highest $S D$ values are observed for the case of EnL-Par-P2.

The statistical analysis has been performed to investigate the relation the statistical effect of (m) (sec) and (f) (manoeuvre/ hr) on $\mathrm{PCE}_{\mathrm{av}}$ value of vehicles manoeuvre for parking of different patterns all over different $\frac{D}{C}$ ratios and its SD. The analysis figures out the Correlation Coefficient 
(CC) and the significance level (P-value). Results summarized in Table 5 illustrates that the average PCE increases with the increase of the value of $(\mathrm{m})$ which is highly correlated to and highly significant for the value of $\mathrm{PCE}_{\mathrm{av}}(\mathrm{CC}=0.9$ and $\mathrm{P}$-value $=1.34 \mathrm{E}-22$ ). On contrary, it is found that (f) is not significant for determining PCE values and has low correlation with $\mathrm{PCE}_{\mathrm{av}}$ $(\mathrm{CC}=-0.05)$. Regression analysis has been performed in order to explain the relation between average $\mathrm{PCE}_{\mathrm{av}}$ and $(\mathrm{m})(\mathrm{sec})$. The relation is expressed as follows:

$$
\mathrm{PCE}_{\mathrm{av}}=1.105+0.037 \mathrm{~m} \quad\left(\mathrm{R}^{2}=0.81\right)
$$

This formula is valid only if the designer searches for an average PCE vale as a function of manoeuvring duration. It does not consider the variation of the $\mathrm{PCE}_{\mathrm{av}}$ with the change of the $\frac{D}{C}$ ratios.

The SD regression formula (Equation 12) is formed using $(\mathrm{m})(\mathrm{sec})$ as an explanatory parameter as it is highly correlated and statistically significant ( $\mathrm{CC}=0.98$ and $\mathrm{P}$-value $=3.56 \mathrm{E}-45) . \mathrm{PCE}_{\mathrm{av}}$ has high correlation coefficient with SD $(\mathrm{CC}=0.84)$ but, it is also highly correlated to $(\mathrm{m})$. Thus, $\mathrm{PCE}_{\mathrm{av}}$ has not been considered as an explanatory parameter in Equation 12 in order to avoid inter-correlation and statistical dependence between explanatory parameters. And only the highly significant parameter is utilized.

$$
\mathrm{SD}=0.009 \mathrm{~m}-0.014 \quad\left(\mathrm{R}^{2}=0.96\right)
$$

Figure 4 and Figure 5 represent two contour charts that show the values of $\mathrm{PCE}_{\mathrm{av}}$ for different $(m)$ and $(f)$ combinations. These charts help traffic designers to estimate an average PCE for cars manoeuvring for legal and illegal parking. It is clear that, for all patterns, $\mathrm{PCE}_{\mathrm{av}}$ increases with the increase of $\mathrm{m}$. On the other hand, for $\mathrm{f}$ range below 20 (manoeuvre/hr), the increase of the value of $\mathrm{f}$ causes a reduction in $\mathrm{PCE}_{\mathrm{av}}$ of illegal patterns while the increase of $f$ for $f$ range above 20 (manoeuvre/hr) has very slight effect on reducing illegal patterns' $\mathrm{PCE}_{\mathrm{av}}$. The same perform of $f$ can be highly and noticed for legal parking patterns of $m$ values above $12.5 \mathrm{sec}$.

Figure 6 illustrates the relation between PCE values of vehicle manoeuvre patterns of legal parking types $\left(\mathrm{PCE}_{\mathrm{L}}\right)$ and $\frac{D}{C}$ in case of $f=10$ (manoeuvre/hr). Generally, EnL-Par-P2 has the highest PCE comparing to other legal manoeuvre patterns while En-L-Par-P4 and En-L-Ang-P2 have the smallest $\mathrm{PCE}_{\mathrm{L}}$. This is related to the time duration of the manoeuvre event $(\mathrm{m})$. All trough the $\frac{D}{C}$ range, $P C E_{r}$ values experience fluctuation. For lower $\frac{D}{C}$ ratios and up to $\frac{D}{C}$ of about $0.33, \mathrm{PCE}_{\mathrm{L}}$ shows a slight upward trend. Then, a sudden drop occurs referred to a sharper increase of the base delay $\left(d_{b}\right)$ of the examined link at this $\frac{D}{C}$ ratio. This allows $\mathrm{PCE}_{\mathrm{L}}$-according to Equation 9 - to hit its lowest value at $\frac{D}{C}$ of about 0.41 . Following, an upward trend takes place supported by the increase of $t_{m}$ reaching the peak value of $\mathrm{PCE}_{\mathrm{L}}$ at $\frac{D}{\mathrm{C}}$ of about 0.74 . From this point, $\mathrm{PCE}_{\mathrm{L}}$ values show a downward trend until $D$ is saturated. At this point, the traffic demand D starts to outrace the value of C`. So, the speed of the flow in case of the manoeuvring event will be constant. And consequently, the application in Equation 9 results in small increase in increase of $t_{m}$ as opposed to the increase of $t_{b}$. All lead to a downward trend in the value of $\mathrm{PCE}_{\mathrm{L}}$ after $\frac{D}{C}$ of 0.74 . For manoeuvring patterns of legal parking on the link under application in this

\section{jitte 207}


paper, $\mathrm{C}^{\backslash}=4050(\mathrm{PCE} / \mathrm{hr} /$ direction $)$ and $\mathrm{v}\left(\mathrm{C}^{\backslash}\right)=\frac{\mathrm{v}_{\text {free }}}{2}=20.05(\mathrm{~km} / \mathrm{hr})$

The behaviour of PCE of manoeuvring vehicles for illegal parking types $\left(\mathrm{PCE}_{\mathrm{IL}}\right)$ throughout $\bar{C}$ range in case of $\mathrm{f}=10$ (manoeuvre/hr) is depicted in Figure 7. Overall, En-IL-Par-P3 and Le-ILPar-P2 have the highest and lowest $\mathrm{PCE}_{\mathrm{IL}}$ respectively comparing to other illegal manoeuvre patterns. PCE of vehicles manoeuvre for illegal parking types coincide with the behaviour of $\mathrm{PCE}_{\mathrm{L}}$ throughout $\frac{D}{C}$ range. The only exception is that in case of illegal on-street parking types the capacity of the section (C) is reduced by an amount of lane capacity (the lane used for parking). And during manoeuvring, the section loses one more lane capacity for the duration of the manoeuvre. Thus, the traffic demand (D) starts to outrace the value of $C^{\backslash}$ at $\frac{D}{C}$ of about 0.69 which is earlier than the case of legal parking. And the downward trend starts after this point. This results in preventing $\mathrm{PCE}_{\mathrm{IL}}$ from increasing so that the peak value is located at $\frac{D}{C}$ of about 0.33 . The values of $C^{\backslash}$ and $\mathrm{v}\left(\mathrm{C}^{\prime}\right)$ are 2025 (PCE/hr/direction) and $10(\mathrm{~km} / \mathrm{hr})$ respectively for manoeuvring patterns of illegal parking of the link under application in this paper.

The analysis of the relation of $\mathrm{PCE}_{\mathrm{L}}$ and $\mathrm{PCE}_{\mathrm{IL}}$ vs. $\left(D_{-} \mathrm{C}\right)$ ratios in case event frequencies of 20, 30, 40 (manoeuvre/hr) indicates the same attributes of the case of 10 (manoeuvre/hr). As statistically shown in Table 6, despite that $\mathrm{PCE}_{\mathrm{L}}$ and $\mathrm{PCE}_{\mathrm{IL}}$ values are not highly correlated to $D_{-}$, both $\mathrm{m}$ and $D_{-}$are significant in determining $\mathrm{PCE}_{\mathrm{L}}$ and $\mathrm{PCE}_{\mathrm{IL}}$. Although $f$ is not highly correlated to either patterns, it is significant for determining the $\mathrm{PCE}_{\mathrm{IL}}$. Figure 6 and Figure 7 show the pattern of progress of PCE value of vehicles perform manoeuvre for legal and illegal parking types for different $\left(D^{-}{ }_{C}\right)$ values in case of $f=10$ (maneuver/hr). Models for predicting the $\mathrm{PCE}_{\mathrm{L}}$ and $\mathrm{PCE}_{\mathrm{IL}}$ value based on ${ }^{{ }_{-}} \mathrm{C}, m$ and $f$ has been developed using a stepwise regression analysis considering powered values up to the six degree of significant parameters. Results showed the following models:

- For vehicles manoeuvring for legal parking types:

$$
\mathrm{PCE}_{\mathrm{L}}=1.0069+0.04776 \mathrm{~m}-0.613 \frac{\mathrm{D}}{\mathrm{C}}+1.21\left(\frac{\mathrm{D}}{\mathrm{C}}\right)^{2}-0.685\left(\frac{\mathrm{D}}{\mathrm{C}}\right)^{6} \quad\left(\mathrm{R}^{2}=0.96\right)
$$

- For vehicles manoeuvring for illegal parking types:

$$
\mathrm{PCE}_{\mathrm{IL}}=0.9889+0.0897 \mathrm{~m}-0.0506 \frac{\mathrm{D}}{\mathrm{C}}+0.0097\left(\frac{\mathrm{D}}{\mathrm{C}}\right)^{2}+0.00089 \mathrm{f} \quad\left(\mathrm{R}^{2}=0.90\right)
$$

The regression models indicate that both $\mathrm{PCE}_{\mathrm{L}}$ and $\mathrm{PCE}_{\mathrm{IL}}$ of both types increase with the increase of $\mathrm{m}$.While $\mathrm{f}$ has no effect on the value of $\mathrm{PCE}_{\mathrm{L}}$, it increase of $\mathrm{PCE}_{\mathrm{IL}}$ takes place as $f$ increases.

In order to investigate the sensitivity of the developed models, the sensitivity coefficient
(Cs) of each independent parameter and the corresponding uncertainty $(U)$ are calculated. Cs describes the rate of varying of the PCE value due to the change of the independent parameter. $U$ reports the uncertainty in the estimated PCE value cased by the standard uncertainty of the each individual parameter. It is the multiplication of $C s$ by the standard 
deviation $(S D)$ of the independent parameter in the model. The combined standard uncertainty $(U c)$ of PCE is estimated by the law of propagation uncertainty:

$$
\mathrm{U}_{\mathrm{c}}=\sqrt{\sum \mathrm{C}_{\mathrm{S}}^{2} \mathrm{U}^{2}}
$$

Sensitivity results shown in Table 7 indicate that among all independent parameter, $\mathrm{PCE}_{\mathrm{L}}$ and $\mathrm{PCE}_{\mathrm{IL}}$ are highly sensitive to the changes in the values of $\frac{D}{C}$ and $\mathrm{m}$ (sec) respectively. $m(\mathrm{sec})$ is the major cause of uncertainty in the predicted PCE for both legal and illegal manoeuvring patterns. $\frac{D}{C}$ and $f$ (manoeuvre) hr) have the same uncertainty influence for $\mathrm{PCE}_{\mathrm{IL}}$. The combined standard uncertainty created by the independent parameter of the predicted values of $\mathrm{PCE}_{\mathrm{IL}}$ is 0.021 . This value represents about 3.5 times the combined standard uncertainty of the predicted values of $\mathrm{PCE}_{\mathrm{L}}$ (0.006).

Table 6

Correlation Coefficient (CC) and P-vale of $(m)(\mathrm{sec}), \frac{D}{\mathrm{C}}$, and $(f)$ (manoeuvre/hr) in Regard with $P C E_{L}$ and $P C E_{I L}$

\begin{tabular}{|c|c|c|c|c|c|c|}
\hline \multirow{2}{*}{} & \multicolumn{2}{|c|}{$\boldsymbol{m}(\mathbf{s e c})$} & \multicolumn{2}{c|}{$\overline{\boldsymbol{D}}$} & \multicolumn{2}{c|}{$f$ (manoeuvre/hr) } \\
\cline { 2 - 7 } & CC & P-value & CC & P-value & CC & P-value \\
\hline PCE $_{\mathrm{L}}$ & 0.938 & 0.0002 & 0.110 & 0.016 & 0.017 & 0.706 \\
\hline PCE $_{\mathrm{IL}}$ & 0.913 & 0.0002 & -0.166 & 0.010 & 0.137 & 0.034 \\
\hline
\end{tabular}

\section{Table 7}

Sensitivity and Uncertainty of PCE Value for Different Independent Parameters Utilized in the Prediction Models of $P C E_{L}$ and $P C E_{I L}$

\begin{tabular}{|c|c|c|c|}
\hline & \multicolumn{3}{|c|}{ Prediction model of PCE } \\
\hline & \multicolumn{2}{|l|}{$m(s e c)$} & $\bar{D}$ \\
\hline Average & \multicolumn{2}{|l|}{8.42} & 0.61 \\
\hline SD & \multicolumn{2}{|l|}{4.93} & 0.28 \\
\hline Cs & \multicolumn{2}{|l|}{$0.047(\mathrm{PCE} / \mathrm{Sec})$} & $0.254\left(\mathrm{PCE} / \frac{\mathrm{D}}{\mathrm{C}}\right)$ \\
\hline$U($ PCE $)$ & 0.23 & & 0.07 \\
\hline \multirow[t]{3}{*}{ Uc } & \multicolumn{3}{|c|}{0.021} \\
\hline & \multicolumn{3}{|c|}{ Prediction model of $P C E_{\mathrm{IL}}$} \\
\hline & $m(s e c)$ & $\bar{D}$ & f (manoeuvre/hr) \\
\hline Average & 4.85 & 0.61 & 25 \\
\hline SD & 0.81 & 0.28 & 11.2 \\
\hline Cs & $0.086(\mathrm{PCE} / \mathrm{Sec})$ & $-0.036\left(P C E / \frac{D}{C}\right)$ & $0.001(\mathrm{PCE} /$ manoeuvre/hr) \\
\hline$U($ PCE $)$ & 0.07 & -0.01 & 0.01 \\
\hline$U c$ & \multicolumn{3}{|c|}{0.006} \\
\hline
\end{tabular}




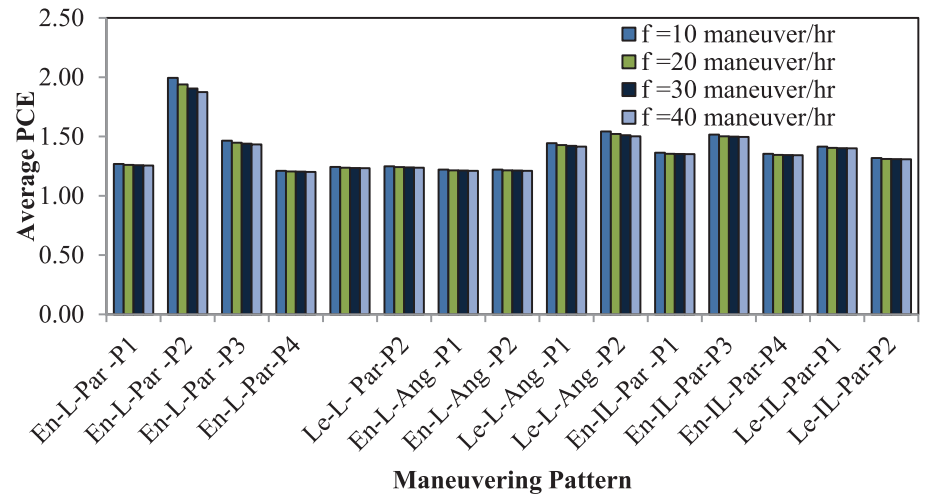

Fig. 2.

Average PCE Value of Different Parking Manoeuvre Patterns for Different Manoeuvre Frequencies

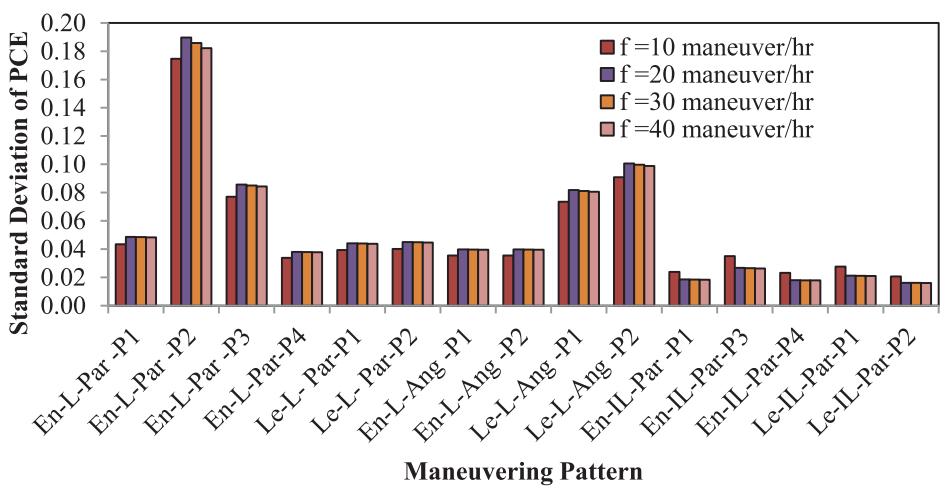

Fig. 3.

Standard Deviation of PCE Value for Different Parking Manoeuvre Patterns and Different Manoeuvring Frequencies

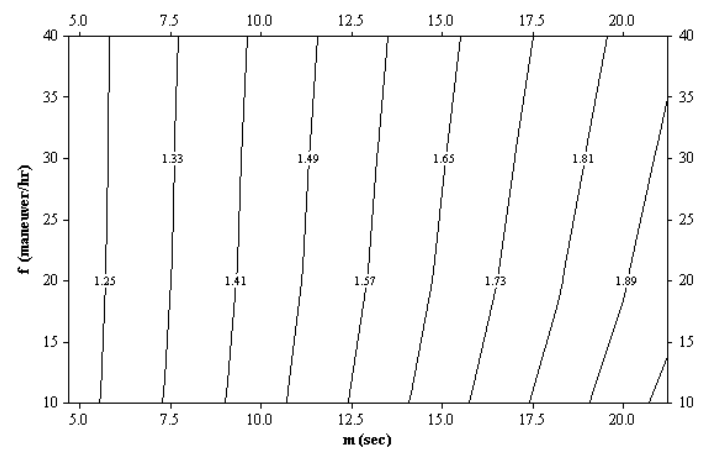

Fig. 4.

Design Chart for Estimating Average PCE for Manoeuvring Vehicles in Case of Legal Parking Types 


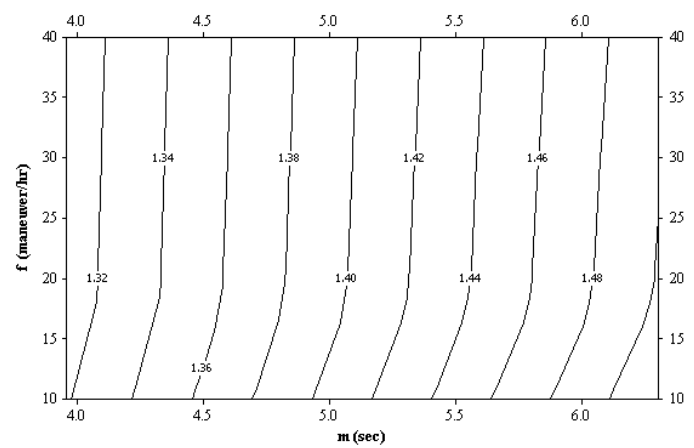

Fig. 5 .

Design Chart for Estimating Average PCE for Manoeuvring Vehicles in Case of Illegal Parking Types

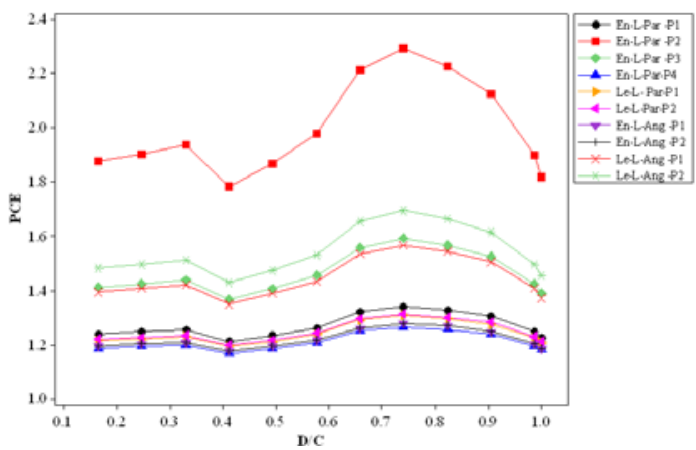

Fig. 6.

Vehicle PCE of Legal Parking Manoeuvre Patterns for Different $\left(\frac{\mathrm{D}}{\mathrm{C}}\right)$ Values in Case of $f=10$ (manoeuvre/hr)

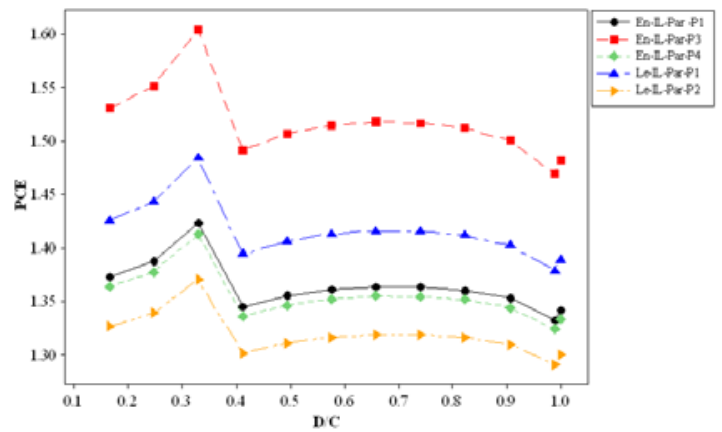

Fig. 7.

Vehicle PCE of Illegal Parking Manoeuvre Patterns for Different $\left(\frac{\mathrm{D}}{\mathrm{C}}\right)$ Values in Case of $f=10$ (manoeuvre/hr) 


\section{Conclusion}

This paper introduces a method for determining the PCE for vehicles that perform a manoeuvre for on-street parking. The $M / M / \infty$ queuing model together with Greenshield's model are used to estimate the effect of the delay and the capacity drop caused by a manoeuvring event on the traffic flow continuity in case of entering or leaving a legal and illegal on-street parking space. Then, a delay-based PCE model is utilized to figure out the manoeuvring vehicle's PCE value. The developed method has been applied for data of 6-lane divided urban street in Delhi-India. The application included 15 different parking manoeuvring patterns of both legal and illegal on-street parking. Related to its high value of the manoeuvre times $(m)$, En-L-Par-P2 has the immense average effect on traffic flow with average PCE (PCEav) of 1.99, 1.94, 1.91, and 1.87 for manoeuvring frequencies $(f)$ of $10,20,30$, and 40 (maneuver/hr) respectively. The statistical analysis for PCEav illustrated that, on contrary of (f) (manoeuvre/hr), (m)(sec) is highly correlated and significant for the value of PCEav (CC $=0.9$ and $\mathrm{P}$-value $=1.34 \mathrm{E}-22$ ). The formula $\mathrm{PCE}_{\mathrm{av}}=1.105+0.037\left(\mathrm{R}^{2}=0.81\right)$ is developed to be used by traffic designers who search for vale of PCEav as a function of parking manoeuvring duration. In addition, two design charts are introduced to show the values of PCEav for different $m$ and $\mathrm{f}$ combinations for both legal and illegal parking types. The effect of to link's volume to capacity ratio $\left(\frac{\mathrm{D}}{\mathrm{C}}\right)$ on the PCE shows that the PCE value of vehicles manoeuvre for legal parking $\left(\mathrm{PCE}_{\mathrm{L}}\right)$ experience fluctuation throughout the $\frac{D}{C}$ range. For lower $\frac{D}{C}$ ratios and up to $\frac{D}{C}$ of about 0.33 , PCEL shows a slight upward trend. Then, a sudden drop occurs referred to a sharper increase of the base delay $\left(d_{b}\right)$ of the examined link at this
$D$ ratio. The smallest PCEL value is noticed at $\frac{D}{C}$ of nearly 0.41 . After, the increase of $\frac{D}{C}$ is accompanied with an increase of PCEL supported by the increase of the link's average travel time $\left(t_{m}\right)$. The peak value of $\mathrm{PCE}_{\mathrm{L}}$ is experienced at $\frac{\mathrm{D}}{\mathrm{C}}$ of 0.74 . After, $\mathrm{PCE}_{\mathrm{L}}$ gets a downward trend. Overall, vehicles performing manoeuvre of type En-LPar-P2 for illegal parking has the highest $\mathrm{PCE}_{\mathrm{L}}$ comparing to other legal manoeuvre patterns, while En-L-Par-P4 and En-LAng-P2 have the smallest $\mathrm{PCE}_{\mathrm{L}}$. PCE of vehicles manoeuvre for illegal parking types $\left(\mathrm{PCE}_{\mathrm{IL}}\right)$ coincide with the behaviour of $\mathrm{PCE}_{\mathrm{L}}$ throughout $\frac{D}{C}$ range. The different is that during illegal maneuvering, the section loses one more lane capacity for the duration of the manoeuvre. Thus, the traffic demand $\mathrm{D}$ starts to outrace the value of $C^{\backslash}$ at $\frac{D}{C}$ of about 0.69 which is earlier than the case of legal parking. Peak value of $\mathrm{PCE}_{\mathrm{IL}}$ is recorded at $\frac{D}{C}$ of about 0.33. En-IL-Par-P3 and Le-IL-Par-P2 have the highest and lowest $\mathrm{PCE}_{\mathrm{IL}}$ respectively as opposed to all illegal parking patterns. Stepwise regression analysis has been implemented for developing explanatory models for predicting the $\mathrm{PCE}_{\mathrm{L}}$ and $\mathrm{PCE}_{\mathrm{IL}}$ value considering the significant levels and correlations of $\frac{D}{\bar{C}}$, m and $\mathrm{f}$. Finally, sensitivity analysis results indicate that $\mathrm{m}(\mathrm{sec})$ is the major cause of uncertainty in the predicted $\mathrm{PCE}_{\mathrm{L}}$ and $\mathrm{PCE}_{\mathrm{IL}}$. The combined standard uncertainty created by the independent parameter of the predicted values of $\mathrm{PCE}_{\mathrm{IL}}$ is 0.021 . This value represents about 3.5 times the combined standard uncertainty of the predicted values of $\mathrm{PCE}_{\mathrm{L}}(0.006)$.

\section{References}

Ahmed, U.; Cetin, M. 2017. Case Studies on Transport Policy Impacts of heavy vehicles on inter-vehicle interactions and passenger car equivalents for tunnel traffic, Case Studies on Transport Policy (August): 0-1. 
Arasan, V.T.; Arkatkar, S.S. 2010. Microsimulation Study of Effect of Volume and Road Width on PCU of Vehicles under Heterogeneous Traffic, Journal of Transportation Engineering 136: 1110-1119.

Benekohal, R. 2000. Delay-based passenger car equivalents for trucks at signalized intersections, Transportation Research Part A 34: 437-457.

Biswas, S.; Subhadip, C. 2017. Kriging-Based Approach for Estimation of Vehicular Speed and Passenger Car Units on an Urban Arterial, Journal of Transportation Engineering Part A: Systems 143(3): 1-11.

Biswas, S.; Chandra, S.; Ghosh, I. 2017. Estimation of Vehicular Speed and Passenger Car Equivalent Under Mixed Traffic Condition Using Artificial Neural Network, Arabian Journal for Science and Engineering 42(9): 4099-4110.

Biswas, S.; Satish, C.; Indrajit, G. 2017. Effects of OnStreet Parking In Urban Context: A Critical Review Effects of On-Street Parking in Urban Context: A Critical Review, Transportation in Developing Economies 3(1): 1-14.

Bulacital, A.; Dizon, F.; Garcia, M.; Valdaz, J. 2013. Comparison of on-street parking management in ErmitaMalate Manila and Makati central business district. In Proceedings of the Eastern Asia Society for Transportation Studies: 9-22.

Cao, J.; Menendez, M. 2015. System dynamics of urban traffic based on its parking-related-states, Transportation Research Part B: Methodological 81: 718-736.

Cao, J.; Menendez, M.; Nikias, V. 2016. The effects of onstreet parking on the service rate of nearby intersections, Journal of Advanced Transportation 50: 406-420.

Cao, N. Y. 2012. Estimating capacity and motorcycle equivalent units on urban roads in Hanoi, Journal of Transportation Engineering 138(6): 776-785.
Cen, X.; Lo, H.K.; Li, L. 2016. A framework for estimating traffic emissions: the development of passenger car emission unit, Transportation Research Part D: Transport and Environment 44: 78-92.

Chandra, S.; Kumar, U. 2003. Effect of Lane Width on Capacity under Mixed Traffic Conditions in India, Journal of Transportation Engineering 129(2): 155-160.

Dhamaniya, A.; Chandra, S. 2017. Influence of Operating Speed on Capacity of Urban Arterial Midblock Sections, International Journal of Civil Engineering 15(7): 1053-1062.

Elkafoury, A.; Negm, A.; Bady, M.; Ichimura, T. 2016. Develop dynamic model for predicting traffic $\mathrm{CO}$ emissions in urban areas, Environmental Science and Pollution Research 23(16): 15899-15910.

Fadairo, G. 2013. Traffic Congestion in Akure, Ondo State, Nigeria: Using Federal University of Technology Akure Road as a case study, International Journal of Arts and Commerce 2(5): 67-76.

Fadhil, A.; Ozen, H. 2017. Characteristics of On-Street Parking in Istanbul, Sigma Journal of Engineering and Natural Sciences 35(4): 575-584.

Giuffre, O. 2016. Passenger car equivalent for heavy vehicles crossing turbo-roundabouts, Transportation Research Procedia 14: 4190-4199. doi: 10.1016/j. trpro.2016.05.390.

Giuffre, O.2018. Simulation modelling practice and theory capacity-based calculation of passenger car equivalents using traffic simulation at double-lane roundabouts, Simulation Modelling Practice and Theory 81(2018): 11-30.

Greenshields, B.D.; Channing, W.; Miller, H. 1935. A study of traffic capacity. In Highway Research Board Proceedings, (1954): 448-477.

Greg, M. 2006. The evidence base for parking policies - a review, Transport Policy 13: 447-457.

\section{jitte 213}


Gu, W.; Vikash, V.; Michael, J.; Saade, N. 2014. On the impacts of bus stops near signalized intersections: models of car and bus delays, Transportation Research Part B 68: 123-140.

Jin, S. 2015. Estimating cycleway capacity and bicycle equivalent unit for electric bicycles, Transportation Research Part A 77: 225-248.

John, I.; Norman, G.; Gilbert, H. 2009. Designing roads that guide drivers to choose safer speeds - Report No. JHR-09-321.

Lee, C. 2015. Developing Passenger-Car Equivalents for Heavy Vehicles in Entry Flow at Roundabouts, Journal of Transportation Engineering 141: 1-7.

Mardani, M. N.; Chandra, S.; Ghosh, I. 2015. Passenger Car Unit of Vehicles on Undivided Intercity Roads in India, Procedia Computer Science 52: 926-931.

Melike, B.; Weihua, X.; Kaan, O.; Duan, Z. 2006. Delay Estimation for Traffic Flow Interrupted by Incidents. In Proceedings of the $86^{\text {th }}$ Annual Transportation Research Conference, 1-18.

Melike, B.; Weihua, X.; Kaan, O. 2009. Modeling traffic flow interrupted by incidents, European Journal of Operational Research 195: 127-138.

Mohan, M.; Chandra, S. 2017. Queue clearance rate method for estimating passenger car equivalents at signalized intersections, Journal of Traffic and Transportation Engineering (English Edition) 4(5): 487-495.

Munawar, A. 2011. Speed and Capacity for Urban Roads, Indonesian Experience, Procedia - Social and Behavioral Sciences 16: 382-387. doi:10.1016/j. sbspro.2011.04.459.

Nassiri, H.; Tabatabaie, S.; Sahebi, S. 2017. Delay-Based Passenger Car Equivalent at Signalized Intersections in Iran, Promet-Traffiç Transportation 29(2): 135-142.
Radhakrishnan, P.; Mathew, T. V. 2011. Transportmetrica Passenger car units and saturation flow models for highly heterogeneous traffic at urban signalised intersections, Transportmetrica 7(2): 141-162.

Saad, Y.; Purnawan, M. 2004. Traffic operations at onstreet parking facilities. In Proceedings of the Institution of Civil Engineers Transport, 157(August): 189-194.

Salini, S.; George, S.; Ashalatha, R. 2016. Effect of Side Frictions on Traffic Characteristics of Urban Arterials, Transportation Research Procedia, 17(December 2014): 636-643.

Samaher, Y. 1999. On-street parking: Effects on traffic congestion, Traffic Engineering \& Control 40(9): 424-431.

Samaher, Y. 2004. Traffic operations at on-street parking facilities. In Proceedings of the Institution of Civil EngineersTransport, 157(3): 189-194.

Sarraj, Y. 2014. Passenger Car Equivalents at Signalized Intersections for Heavy and Medium Trucks and Animal Driven Carts in Gaza, International Journal of Emerging Technology and Advanced Engineering 4: 80-88.

Sasikumar, S.; Ashalatha, R. 2018. Development of passenger car unit based on acceleration noise for urban arterials. In Proceedings of the Institution of Civil Engineers, 171(6): 331-338.

Stephen, I.; Tom, R. 2006. Parking, Transport Policy 13: 445-446.

TRB. 2010. Highway Capacity Manual. Fifth edition, Washington, D.C., National Research Council.

Xiaofei, Y.; Jun, C. 2011. Traffic Delay Caused by Curb Parking Set in the Influenced Area of a Signalized Intersection. In Proceedings of the ICCTP, 566-578.

Yeung, J. S.; Wong, Y. D.; Secadiningrat, J. R. 2015. Laneharmonised passenger car equivalents for heterogeneous expressway traffic, Transportation Research Part A 78: 361-370. 